\section{MIGRACIÓN DE MÉDICOS PERUANOS A ESPAÑA, 2005-2009}

\section{MIGRATION OF PERUVAN PHYSICIANS TO SPAIN, 2005-2009}

\author{
Diego A. Bernardini-Zambrini1,2,a , José Francisco \\ García Gutierrez ${ }^{1,3, a}$, Percy Mayta-Tristán ${ }^{4, b}$
}

Sr. Editor. La migración de profesionales de la salud es un fenómeno que se ha dado siempre y que ahora, al poder ser cuantificado e incluido en la agenda de la política sanitaria actual, ha cobrado mayor relevancia. En el caso especial de los médicos, este flujo migratorio suele ser unidireccional, esto significa migrar desde un lugar con menor desarrollo socioeconómico a uno donde las condiciones son mejores ${ }^{(1)}$. Esta situación genera un desafío para los sistemas de salud, ya que el reto es llevar a los profesionales de salud a los lugares con mayor necesidad (2).

En los últimos años ha cobrado relevancia el "efecto llamada" que ha tenido para algunos países de América Latina el sistema de salud español a través del programa de formación MIR -Médico Interno Residente- para la especialización médica. Por otro lado, España es el principal país de destino migratorio de los futuros médicos peruanos ${ }^{(3)}$; sin embargo, el número total de médicos peruanos que han emigrado a España al programa MIR no ha sido cuantificado.

Por ello, analizamos la participación de médicos provenientes de Perú en el sistema MIR español durante el periodo comprendido entre los años 2005 - 2009. Se revisó la información pública que dispone el Ministerio de Sanidad, Política Social e Igualdad de España para el periodo de estudio.

Perú es el país que más médicos extranjeros aportó a las pruebas de selección MIR desde el año 2001 al 2009 con un total de 3090 graduados en condición de optar a una plaza, seguido por Colombia con 2622, Republica Dominicana 1106 y México 905. De este total, 2866 $(92,8 \%)$ correspondieron al periodo 2005 - 2009, evidenciándose un incremento año a año de postulantes y electores (Tabla 1). Un aspecto importante relacionado con las especialidades elegidas es que dos de cada cinco médicos peruanos eligieron una plaza de medicina familiar, proporción que ha ido disminuyendo; por otro lado, el índice de personas que consiguen una plaza en relación con el total de postulantes ha ido decayendo.

Estas cifras indican que Perú es el principal país "donante" de médicos al sistema de especialización español. Lo primero que se observa es que esta "fuga de cerebros" se ha dado de manera continua en los últimos diez años, con un mayor incremento en el último quinquenio, situación similar a la de Republica Dominicana y México. Este hallazgo sobre la predisposición a migrar en profesionales peruanos estaría asociado con distintos motivos, pero la motivación primaria sería económica ${ }^{(3)}$, dada la inequidad remunerativa existente en el sistema de salud peruano ${ }^{(4)}$.

En el flujo de migración de un país a otro, el efecto de filtro lo establece el país receptor, a través de la regulación según sus necesidades. Por lo cual es importante considerar que el flujo de salida se mantendrá constante mientras las condiciones en el mercado receptor sean favorables; en todo caso, una regulación más estrecha hará que quienes puedan optar a esas plazas sean

Tabla 1. Evolución de la participación de médicos graduados en Perú en el examen MIR de España, 2005-2009.

\begin{tabular}{|c|c|c|c|c|c|}
\hline \multirow[t]{2}{*}{ Año } & \multicolumn{3}{|c|}{ Examen MIR } & \multirow{2}{*}{$\begin{array}{c}\text { Índice asignados / } \\
\text { postulantes }\end{array}$} & \multirow{2}{*}{$\begin{array}{c}\text { Especialidad } \\
\text { Medicina Familiar } \\
\text { N }(\%)\end{array}$} \\
\hline & Admitidos & Electores & Asignados & & \\
\hline 2005 & 340 & 252 & 169 & 0,497 & $81(47,9)$ \\
\hline 2006 & 578 & 455 & 243 & 0,420 & $116(47,7)$ \\
\hline 2007 & 940 & 596 & 335 & 0,356 & $146(43,6)$ \\
\hline 2008 & 978 & 701 & 422 & 0,413 & $188(44,6)$ \\
\hline 2009 & 1140 & 862 & 403 & 0,354 & $148(36,7)$ \\
\hline
\end{tabular}

MIR: médico interno residente.

\footnotetext{
Organización Panamericana de la Salud. Washington DC, EE.UU.

Facultad de Medicina, Universidad de Buenos Aires. Buenos Aires, Argentina.

Escuela Andaluza de Salud Pública. Granada, España.

4 Escuela de Medicina, Universidad Peruana de Ciencias Aplicadas. Lima, Perú

Médico, Doctor en Medicina; ${ }^{\text {b }}$ Médico salubrista
} 
quienes estén mejor preparados, es decir, dadas las condiciones actuales y las proyecciones establecidas, consideramos que seguirá existiendo este flujo migratorio de médicos peruanos al sistema de especialización MIR español.

El segundo punto por considerar es lo que sucede con este médico extranjero, cuando termina su formación en el sistema español, existen tres opciones: (a) se integra al sistema de salud español, (b) retorna a su país de origen o (c) migra a un país distinto.

España tiene un sistema nacional de salud descentralizado con larga tradición en atención primaria y es un pilar del estado de bienestar, por lo que la medicina pública es la primera opción de todo médico especializado $y$, en particular, para los egresados de medicina familiar. El orientarse a la medicina privada es una opción que está más relacionada con retornar a su país o migrar a otro, que trabajar de esa forma en España.

No tenemos datos sobre cuantos de los médicos peruanos formados en el MIR han retornado a su país, no se han encontrado políticas desde el Estado para incentivar su retorno, por lo que suponemos que aquellos que lo hacen serían principalmente para ejercer en la práctica privada.

Otra opción, sería la de "utilizar" a España como país de capacitación y tránsito para luego poder migrar a un país que garantice mejores condiciones y con tradición más sólida en su sistema de salud como podrían ser Alemania o el Reino Unido (como lo podrían hacer algunos futuros médicos españoles) ${ }^{(5)}$; sin embargo, no existen estudios al respecto y futuras investigaciones deberían abordar el tema.

En conclusión, evidenciamos un flujo continuo y en crecimiento de médicos graduados en Perú que se insertan en el sistema de formación especializada de España (MIR), se requieren estudios que evidencien cuál es el futuro laboral de estos médicos, si es que se insertan al sistema de salud español, retornan al Perú o migran a otros países, para luego poder analizar las consecuencias de esta situación para ambos sistemas de salud.

\section{Fuente de financiamiento}

Autofinanciado.

\section{Conflictos de interés}

Los autores declaran no tener conflictos de interés en la publicación de este artículo. Las opiniones y juicios vertidos en este escrito, corresponden a la opinión de sus propios autores y no representa la posición de las instituciones a la que pertenecen.

\section{REFERENCIAS BIBLIOGRÁFICAS}

1. Stillwell B, Diallo K, Zurn P, Vujicic M, Adams O, Dal Poz M. Migration of health-care workers from developing countries: strategic approaches to its management. Bull World Health Organ. 2004;82(8):595-600.

2. World Health Organization. Increasing access to health workers in remote and rural areas through improved retention. Global policy recommendations. Geneva: WHO; 2011.

3. Mayta-Tristán P, Dulanto-Pizzorni A. Prevalencia y factores asociados con la intención de emigración en internos de medicina de una universidad pública, Lima 2007. Rev Peru Med Exp Salud Publica. 2008; 25(3): 274-8.

4. Pardo K, Andia M, Rodriguez A, Perez W, Moscoso B. Remuneraciones, beneficios e incentivos laborales percibidos por trabajadores del sector salud en el Perú: análisis comparativo entre el Ministerio de Salud y la Seguridad Social, 2009. Rev Peru Med Exp Salud Publica. 2011;28(2):342-51.

5. Bernardini-Zambrini D, Barengo N, Bardach A, Hanna M, Nuñez JM. ¿Migrar o no migrar? ¿Qué pasará com nuestra próxima generación de médicos? Estudio sobre causas y motivos de estudiantes avanzados de medicina de 11 universidades de España. Aten Primaria. 2011;43(5):222-6.

Correspondencia: Diego Bernardini Zambrini

Dirección: 525 Twenty third street, NW, Washington DC 20037 Teléfono: 001-202-974-3767

Correo electrónico: bernardd@paho.org

\section{POLIOMIELITIS PARALÍTICA CAUSADA POR LA VACUNA ORAL SABIN: ¿TIEMPO DE CAMBIAR DE VACUNA?}

\section{PARALITIC POLIOMYELITIS CAUSED BY THE ORAL SABIN VACCINE: TIME FOR A VACCINE CHANGE?}

Wilfredo Gutiérrez ${ }^{1, a}$

Sr. Editor. En mayo de 1985 la Oroganización Panamericana de la Salud-OPS emprende la estrategia de interrupción de la transmisión del virus salvaje de la polio en el continente americano. Ya para esa época, 22 de los 36 países del continente estaban libres de poliovirus salvaje autóctono, comenzando por las Islas Caymán en 1958 y Cuba y Guyana en 1962. En agosto de 1991 se detecta el último caso en Perú (Pichanaqui, Junín), que a su vez fue el último en toda América, por lo que en septiembre de

\footnotetext{
Instituto Cuánto. Lima, Perú.

Médico cirujano, Magíster en Salud Pública
} 